\title{
No relationship exists between PBP 2a amounts ex- pressed in different MRSA strains obtained clinically and their $\beta$-lactam MIC values
}

\author{
Md. Anowar Khasru Parvez', Hirofumi Shibata', Tatsuro Nakano', Shingo Niimi², \\ Nobuo Fujii ${ }^{3}$, Naokatu Arakaki', and Tomihiko Higuti ${ }^{1}$ \\ ${ }^{1}$ Department of Molecular Cell Biology and Medicine, Institute of Health Biosciences, the University \\ of Tokushima Graduate School, Tokushima, Japan ; Division of Biological Chemistry and Biologicals, \\ National Institute of Health Sciences, Tokyo, Japan ; and ${ }^{3}$ Department of Media Design, Faculty of \\ Human Life Sciences, Tokushima Bunri University, Tokushima, Japan
}

\begin{abstract}
After establishing a linear relationship between the amount of penicillinbinding protein (PBP) 2a and membrane proteins of methicillin-resistant Staphylococcus aureus (MRSA) COL by dot-blot analysis using an antibody against PBP 2a, we determined the PBP 2a quantities in membrane fractions prepared from 14 different MRSA cells. Methicillin-sensitive $S$. aureus ATCC 6538 P was used as a quality control strain. The amounts of PBP 2a diverged among the strains, and no relationship to $\beta$-lactam MIC values were observed in the corresponding strains. J. Med. Invest. 55 : 246-253, August, 2008
\end{abstract}

Keywords : Methicillin-resistant Staphylococcus aureus (MRSA), Penicillin-binding protein (PBP) 2a, $\beta$-lactam MIC values

\section{INTRODUCTION}

Methicillin-resistant Staphylococcus aureus (MRSA) strains account for $>60 \%$ of $S$. aureus clinical isolates in Japan, Singapore, and Taiwan, $>50 \%$ in Italy and Portugal, and 34\% in the United States (1). MRSA isolates have an additional transpeptidase, a $78 \mathrm{Kd}$ class $\mathrm{B}$ penicillin-binding protein (PBP) named PBP 2' (PBP 2a), which has a decreased affinity to $\beta$-lactams (2-5). PBP $2 \mathrm{a}$ is encoded by a mecA gene of unknown origin $(6,7)$. Usually, susceptible strains do not have the gene of this PBP (3). Although it is generally believed that PBP 2a is essential for conferring broad spectrum resistance to virtually all clinically used $\beta$-lactam

Received for publication June 24, 2008 ; accepted July 4, 2008.

Address correspondence and reprint requests to Tomihiko Higuti, Ph.D. Professor of Molecular Cell Biology and Medicine, Institute of Health Biosciences, the University of Tokushima Graduate School, Sho-machi, Tokushima 770-8505, Japan and Fax : +81-88-633-9550. antibiotics (8-11) in $S$. aureus, the $\beta$-lactam (e.g., methicillin) MIC for resistant strains varies widely, from $3.1 \mu \mathrm{g}$ to $1600 \mu \mathrm{g} / \mathrm{ml}$.

Moreover, MRSA isolates with a low level of resistance show a peculiar, so-called heterogeneous expression of resistance. Our previous population analysis study of 20 MRSA strains using oxacillin revealed that three strains $(20-22)$ were heteroMRSA, exhibiting relatively low methicillin MICs, ranging from 256 to $128 \mu \mathrm{g} / \mathrm{ml}$, while all the others were homo-MRSA (high-level methicillin MICs, $\geq 1024 \mu \mathrm{g} / \mathrm{ml})(12)$.

It was reported (13) that transposon mutants of MRSAs, despite the massive reductions in the mutants' methicillin MIC, retained an intact mecA and its product, $\mathrm{PBP} 2 \mathrm{a}$. The inserts were in genes involved in staphylococcal cell wall synthesis (13). In a report with heterogeneously resistant strains, cells with increased resistance levels present at low frequency (typically, $10^{-4}$ to $10^{-7}$ ) in the form of one or more subpopulations, still produced normal amounts 
of PBP 2a (14).

However, there has been little study of low- and high-resistance phenotypes of the MRSA strains to $\beta$-lactams in relation to the organism-producing levels of PBP 2a. Indeed, we proposed a two-step model for the sequence of a high-level resistance mechanism of MRSA to $\beta$-lactams $(12,15)$. Since the ability to produce PBP $2 \mathrm{a}$ is essential for the methicillin resistance of $S$. aureus, it is conceivable that knowing the amount of PBP 2a produced by the strains of high- and low-resistance groups might aid in understanding PBP 2a's role in resistance to $\beta$-lactam antibiotics. In this paper, we describe a linear relationship between the protein amount of the MRSA COL (a reference strain) and the PBP 2a quantity by dot-blot analysis using an antibody against PBP 2a. Moreover, since the relationship between PBP 2a amount and $\beta$-lactam MICs has not yet been well examined in the different clinical strains, this study aims to find out whether or not any correlation exists.

\section{MATERIALS AND METHODS}

\section{S. aureus strains}

Clinical strains of MRSA (strains 1-7, 9, 20-22) were kindly supplied by the late Dr. Toru Usui (Kyoto Microbiological Institute, Kyoto, Japan). Strain N315 and vancomycin (VCM) intermediateresistance strains (VISA) Mu3 and Mu50 were kind gifts from Dr. Keiichi Hiramatsu (Juntendo University, Tokyo, Japan), and strain COL was from Dr. John J. Iandolo (University of Oklahoma Health Sciences Center, Tulsa, OK, USA). Methicillinsensitive $S$. aureus (MSSA) ATCC 6538P was used as a reference strain. Some properties of the clinical strains used in the present study were determined previously (12).

\section{Drug susceptibility assay of bacterial isolates}

Bacterial susceptibility to antibacterial agents was measured in vitro by employing a standard twofold plate-dilution method using BBL ${ }^{\mathrm{TM}}$ Mueller-Hinton II agar (Becton Dickinson, Franklin Lakes, NJ, USA) supplemented with $25 \mu \mathrm{g} / \mathrm{ml}$ of $\mathrm{Ca}^{2+}, 50 \mu \mathrm{g} /$ $\mathrm{ml}$ of $\mathrm{Mg}^{2+}$, and $2 \% \mathrm{NaCl}$ (CA-MHA) (12). Following overnight incubation of test strains at $37^{\circ} \mathrm{C}$ in $\mathrm{MHB}$, cultures were diluted with $0.85 \% \mathrm{NaCl}$, and then the bacteria (about $10^{6} \mathrm{CFU} / \mathrm{ml}$ ) were applied with an inoculator onto the surfaces of $10 \mathrm{ml}$ agar layers containing the antibiotics. The plates were incubated at $37^{\circ} \mathrm{C}$ for $48 \mathrm{~h}$ and were checked for antibacterial susceptibility. The MIC was recorded as the lowest concentration of the antibiotic that completely inhibited growth.

\section{Dot-blotting for detection and quantification of PBP 2 a followed by membrane protein preparation}

For the detection of PBP 2a, an antibody against PBP 2a was prepared with a peptide of PBP 2a (16, $17)$; details of the procedure were described previously (15). The strains of MRSA were incubated for $5 \mathrm{~h}$ at $37^{\circ} \mathrm{C}$ in a $\mathrm{BBL}^{\mathrm{TM}}$ Brain Heart Infusion (BHI) broth (Becton Dickinson). The cells were subsequently harvested from the culture after washing three times with washing buffer $(50 \mathrm{mM}$ Tris$\mathrm{HCl}, \mathrm{pH} 7.5$, and $145 \mathrm{mM} \mathrm{NaCl}$ ) by centrifugation at $4,500 \times \mathrm{g}$ for $15 \mathrm{~min}$ at $6^{\circ} \mathrm{C}$. Then the pellet was resuspended in the same buffer, and $2.4 \mathrm{ml}$ cell suspension was treated with $24 \mathrm{ml}$ of lysis buffer containing $50 \mathrm{mM}$ Tris- $\mathrm{HCl}$ (pH 7.5), $50 \mu \mathrm{g} / \mathrm{ml}$ lysostaphin (Sigma Chemical, St. Louis, MO, USA), $10 \mathrm{mg} / \mathrm{ml}$ DNase I (Roche Diagnostics, Indianapolis, IN, USA), $5 \mathrm{mM} \mathrm{MgCl}$, and $100 \mathrm{mM}$ phenylmethylsulfonyl fluoride (PMSF ; Sigma Chemical) for $1 \mathrm{~h}$ at $37^{\circ} \mathrm{C}$. After centrifugation at $45,000 \times g$ at $6^{\circ} \mathrm{C}$ for $1 \mathrm{~h}$, the precipitant was dissolved with 10 $\mathrm{mM}$ phosphate buffer, $\mathrm{pH} 7.0$, containing $100 \mathrm{mM}$ PMSF and diluted $(1: 25)$ with dilution buffer containing $10 \mathrm{mg} / \mathrm{ml}$ DNase I and $200 \mathrm{mM} \mathrm{MgCl}$. Crude debris were removed by centrifugation at $4,500 \times \mathrm{g}$ for $1 \mathrm{~h}$ at $6^{\circ} \mathrm{C}$, and the resultant supernatant was centrifuged at $45,000 \times g$ at $6^{\circ} \mathrm{C}$ for $1 \mathrm{~h}$. The precipitant was suspended with $10 \mathrm{mM}$ phosphate buffer, $\mathrm{pH}$ 7.0, containing $100 \mathrm{mM}$ PMSF and purified by centrifugation at $45,000 \times g$ at $6^{\circ} \mathrm{C}$ for $1 \mathrm{~h}$. Finally the membrane fraction was dissolved with $50 \mu \mathrm{l}$ of $10 \mathrm{mM}$ phosphate buffer, $\mathrm{pH}$ 7.0. Protein concentrations were determined using a colorimetric method with bovine serum albumin as a standard $(15,18)$. To investigate the relationship between the PBP 2a amount and the membrane protein fractions, $0.2 \mu \mathrm{g}, 0.5 \mu \mathrm{g}, 1.0 \mu \mathrm{g}$, and $2.0 \mu \mathrm{g}$ membrane fractions from MRSA COL (a reference strain) were transferred to nitrocellulose membrane (Bio-Rad Laboratories, Hercules, CA, USA) using the Bio-Dot-SF Microfiltration Apparatus (BioRad) according to the manufacturer's instructions. PBP 2a was identified by the chemiluminescence method as described with the ECL Plus Western Blotting kit (Amersham Biosciences, Piscataway, NJ, USA). Repeated experiments were done to confirm the results. 
To determine the PBP 2a quantities in membrane fractions of different MRSA clinical strains, $1.0 \mu \mathrm{g}$ protein was used following the procedure described above with MSSA ATCC 6538P as a quality control strain.

\section{Statistical analysis}

To assess the correlation between PBP 2a levels of the strains examined and the corresponding MICs of $\beta$-lactams, the Pearson correlation coefficient was calculated by using a linear model with terms for the two variables.

\section{RESULTS}

\section{Antibacterial activity}

All of the MRSA strains examined in the present study were resistant to $\beta$-lactams (e.g., methicillin MIC, 64 - >1,024 $\mu \mathrm{g} / \mathrm{ml})$, but strain N315 showed a low MIC $(8 \mu \mathrm{g} / \mathrm{ml})$, which was close to those of $\beta$-lactam-susceptible strains. Using a PCR technique, we confirmed that all the MRSA strains (100\%), including N315, carried the mecA gene.

\section{Detection and quantification of PBP $2 a$ with dot- blot}

Based on the previous result that a single band (molecular mass, about $76 \mathrm{kD}$ ) was detected by means of sodium dodecyl sulfate-polyacrylamide gel electrophoresis of a membrane fraction of MRSA (10 $\mu \mathrm{g}$ of protein) followed by Western blotting analysis with the antibody against the peptide of PBP 2a (15), we conducted the study on detection and quantification of PBP 2a with dot-blot. In the present work, PBP 2a was detected in all strains of MRSA examined, including pre-MRSA strain N315, with MSSA ATCC 6538P as a negative control strain. For the quantification study, we first examined the relationship between the PBP 2a amount and membrane proteins prepared from MRSA COL by dot-blot analysis using an antibody against PBP 2a.

As shown in Fig. 1, the relationship between PBP 2a and membrane proteins of MRSA COL was linear. Hence, using immunoblotting we determined the PBP 2a quantities from membrane fractions prepared from the different clinical MRSA cells, with MSSA ATCC 6538P as a quality control strain. The PBP 2a amounts diverged among the strains (Fig. 2). The three heteroresistant clinical strains (20-22) had higher amounts than the homoresis- tant clinical strains, except for strains 3 and 6 . However, it must be pointed out that the amounts of PBP 2a varied among the three heteroresistant strains (20-22) (Fig. 2). In the present work, VISA strain Mu3 exhibited the highest levels of PBP 2a among the examined MRSA strains (Fig. 2).

As Fig. 3 clearly demonstrates, however, the resistant phenotypes of MRSA to $\beta$-lactams were unrelated to the organism-producing level of PBP $2 \mathrm{a}$. Strains N315 and 1 showed similar PBP 2a quantities, although their respective methicillin MICs were $8 \mu \mathrm{g} / \mathrm{ml}$ and $>1024 \mu \mathrm{g} / \mathrm{ml}$. Among the homoresistant strain, MRSA 6 showed the highest value of the PBP 2a although its oxacillin and cephapirin MICs were $128 \mu \mathrm{g} / \mathrm{ml}$ and $64 \mu \mathrm{g} / \mathrm{ml}$ less than MICs of MRSA isolate $2(512 \mu \mathrm{g} / \mathrm{ml}$ and $128 \mu \mathrm{g} / \mathrm{ml}$ respectively) (Fig. 3). However, the cefotaxime MIC was found to be higher $(1024 \mu \mathrm{g} / \mathrm{ml})$

(A)

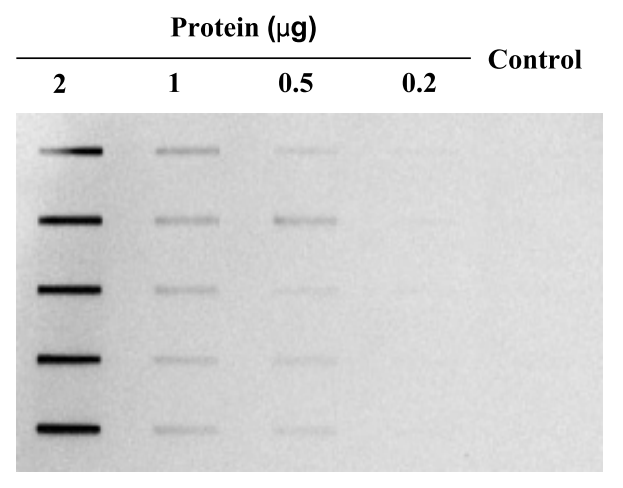

(B)

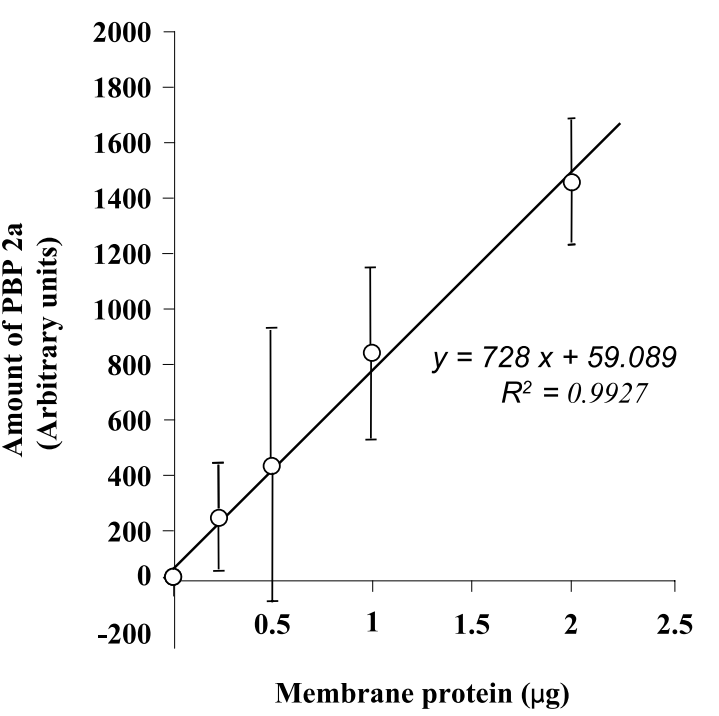

Fig. 1. Immuno-blot analysis of PBP 2a in membrane fraction prepared from MRSA COL. Cell membrane proteins of MRSA COL were prepared, purified, and quantified as described in Materials and Methods. (A) Western blot analysis of different concentrations of proteins $(0.2 \mu \mathrm{g}, 0.5 \mu \mathrm{g}, 1.0 \mu \mathrm{g}$, and $2.0 \mu \mathrm{g})$. PBP 2a was detected by the use of ECL Plus. The result shows five independent experiments. (B) A linear relationship between the amount of PBP $2 \mathrm{a}$ and membrane fraction of MRSA COL. 
(A)

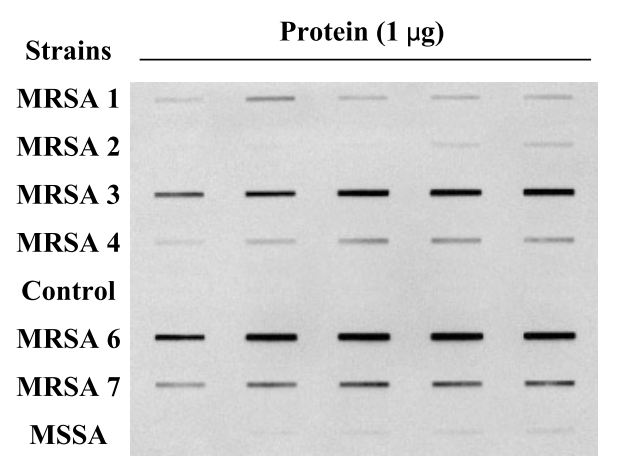

(B)

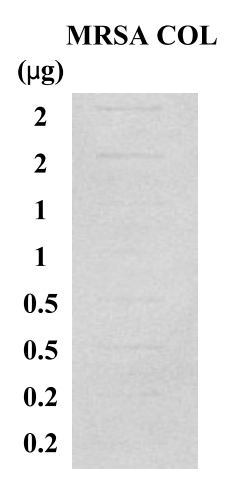

(C)

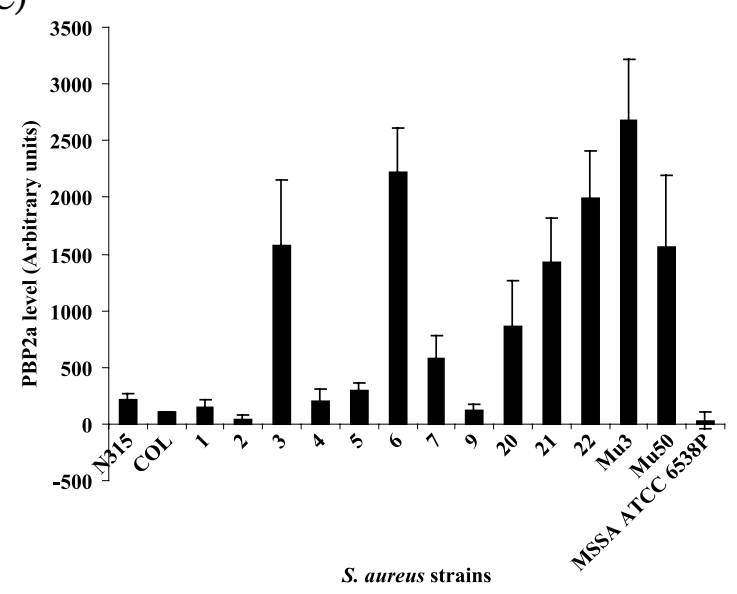

Fig. 2. Amounts of PBP 2a in the cell membranes of different clinical strains of MRSA. (A) A typical demonstration of dot-blotting analysis of PBP 2a level. The membrane fractions of 6 strains of MRSA and MSSA (1 $\mu \mathrm{g}$ of protein) were applied. MSSA ATCC 6538P was employed as a quality control strain. The result shows five independent experiments. (B) Dot-blotting analysis of the membrane protein prepared from MRSA COL was used for the demonstration of the PBP 2a level of the other strain shown in (A). (C) Bar diagram of PBP 2a amounts of different MRSA strains obtained clinically with MSSA ATCC 6538P as a quality control strain.

(A)

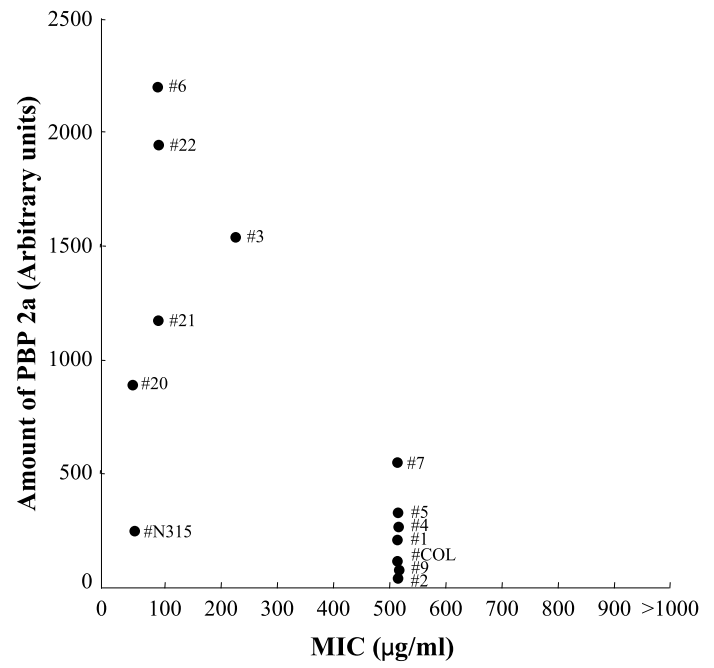

(C)

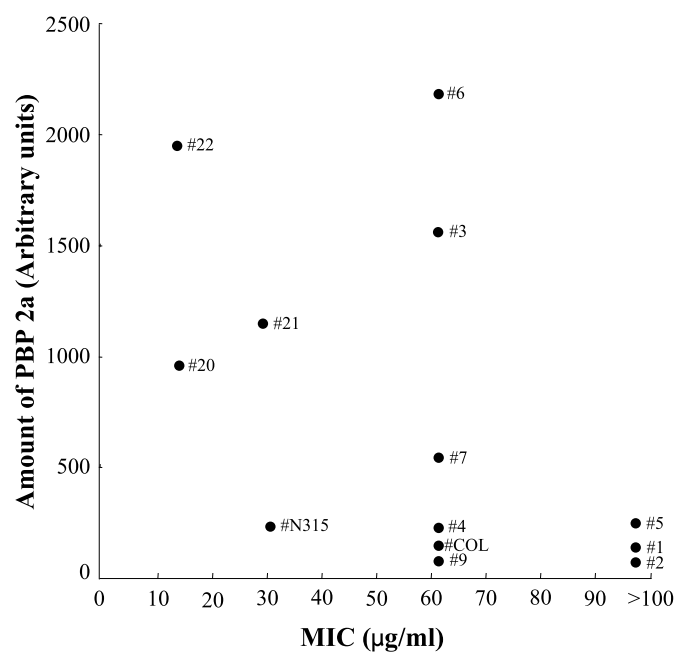

(B)

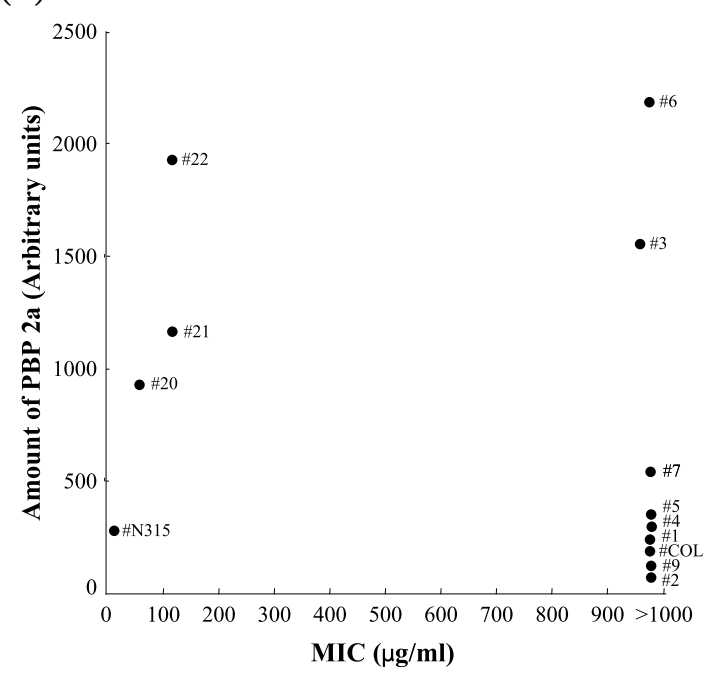

(D)

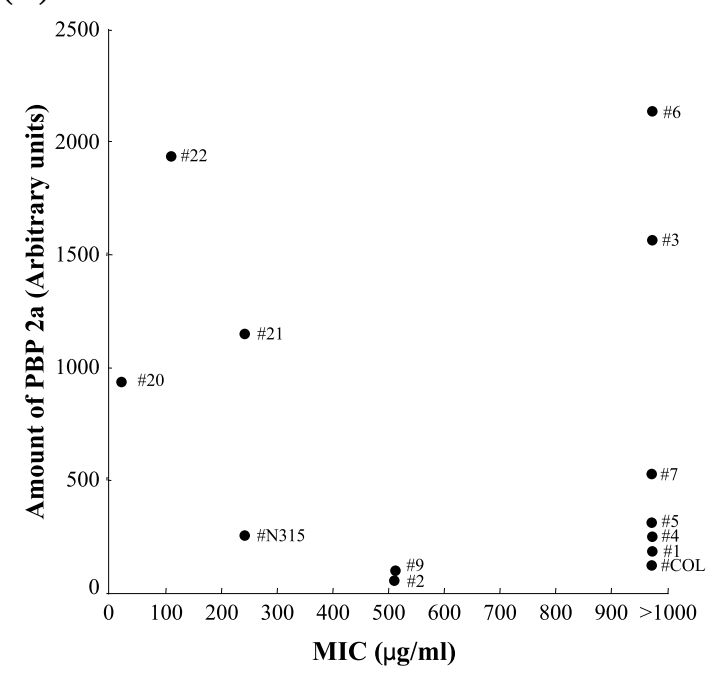

Fig. 3. Relationship between PBP 2a levels and MIC values of oxacillin (A), methicillin (B), cephapirin (C), and or cefotaxime (D) of 13 different strains of MRSA. 
in strain 6 than MRSA isolate of $2(512 \mu \mathrm{g} / \mathrm{ml})$. Discrepancy was also found with heteroresistant strain as shown in Fig. 3.

\section{Statistical analysis}

To assess the correlations between the PBP 2a levels of the strains examined and the corresponding MICs of $\beta$-lactams, we assumed a linear model with terms for the two variables and calculated the Pearson correlation coefficients for the drugs, with the exception of that for methicillin. The coefficients were -0.677 for oxacillin, -0.482 for cephapirin, and -0.153 for cefotaxime. The corresponding probability values ( $\mathrm{p}$-values, two-tailed) were $0.011,0.095$, and 0.618 , respectively. For the latter two drugs, the results of this study suggest that there are no linear relationships between the PBP 2a levels of the MRSA strains examined and the drugs' MICs. However, in the case of oxacillin, the resulting $p$-value suggests that we could not exclude a linear relationship between the PBP 2a levels and the drug MICs.

\section{DISCUSSION}

A wide range of $\beta$-lactam MICs from the level of MSSA to $>4,000 \mu \mathrm{g} / \mathrm{ml}$ has been reported in clinical strains of MRSA, despite the fact that these MICs have an altered PBP 2a that $\beta$-lactam antibiotics do not inhibit at chemotherapeutic levels $(9,10,14$, 19). In the present study, the range of $\beta$-lactam resistance levels for MRSA also varied widely. For example, the MICs of oxacillin and cefotaxime were $64 \mu \mathrm{g} / \mathrm{ml}$ to $512 \mu \mathrm{g} / \mathrm{ml}$ and $32 \mu \mathrm{g} / \mathrm{ml}$ to 1024 $\mu \mathrm{g} / \mathrm{ml}$, respectively. On the basis of bacterial susceptibility to $\beta$-lactam antibiotics, methicillinresistant $S$. aureus isolates could be classified into low- and high-resistance groups. Again, various phenotypic expressions of resistance (homogeneous or heterogeneous) have been reported in clinical isolates of MRSA $(12,20,21)$. This leads to the question of whether or not PBP 2a production alone is related to the expression of high-level methicillin resistance in $S$. aureus. To answer this, we determined the amounts of PBP 2a in different MRSA isolates obtained clinically, following the procedure described in Materials and Methods.

Although Araj, et al. (22) reported that the reliable detection of MRSA cannot be based solely on the detection of the mecA gene in S. aureus, the presence of clinical isolates examined in the pre- sent study, previously classified as methicillinresistant, were confirmed by the PCR finding that all of them carry the mecA gene, including strain N315 (12, 23, 24).

In the present study, we provide clear evidence with clinically isolated strains that there is no relationship between PBP 2a amount and $\beta$-lactam MIC value. First, the amount of PBP 2 a varied widely among the highly and homogeneously resistant strains 1-7 and 9 (methicillin MIC $\geq 1024 \mu \mathrm{g} / \mathrm{ml}$ ). The PBP 2a quantities were higher in strains 3,6 , and 7 than in the others. Second, strains 20-22 produced significantly high amounts of PBP 2a, yet exhibited only low-level heterogeneous resistance. Comparing strains 20 and 22, we found that, even though the cephapirin MICs were the same $(16 \mu \mathrm{g} /$ $\mathrm{ml}$ ), the cellular amount of PBP 2a was much higher in the latter than in the former.

This is supported by the statistical analysis. For cephapirin and cefotaxime, the results of this study suggest that there are no linear relationships between PBP 2a levels and drug MICs. Unfortunately, in the case of oxacillin, we failed to exclude a certain correlation between the two variables. With respect to oxacillin, possibly as well as methicillin, the strains employed in this study were divided into two groups : those having drug MICs of $512 \mu \mathrm{g} / \mathrm{ml}$ (> 1,024 $\mu \mathrm{g} / \mathrm{ml}$ for methicillin) and those having drug MICs of less than that. Overall, this appears to fit to a significant inverse correlation between the two variables. On the other hand, the PBP 2a amounts of the members of both groups ranged from low to high levels, thus demonstrating no particular relationship between the two parameters.

PBP 2a is encoded by the mecA gene, which is regulated by two upstream genes, mecRl and mecI (25). They can express mecA constitutively, or they can use the $\beta$-lactamase regulatory genes, blaRl and blaI, to optimally express mecA, since BlaR1 is a strong inducer of $m e c A$ whereas BlaI is a weak repressor (25-28). One report described that the uninduced amounts of PBP 2a from penicillinaseproducing parents were lower than those for penicillinase-negative variants (29). In the present study, similar results were found with $\beta$-lactamasenonproducing heteroresistant isolates (strains 20-22) that lack both regulatory genes mecRI/mecI and blaRI/blaI (12). In contrast with that report, we found that the $\beta$-lactamase-producing highresistance clinical isolates exhibited relatively less PBP 2a, except for strain 1, a $\beta$-lactamase nonproducing homoresistant strain with a lower amount 
of cellular PBP 2a. However, strain 1 carried mecRI/ mecI regulatory genes, according to our previous report (12).

The apparent noncorrelation between MIC and the amount of PBP 2a suggests that some other, unknown factor contributes to the increased MIC. According to Murakami, et al. (29) the existence of an unknown factor was suggested previously from the observation that heterogeneously resistant strains produced significant amounts of PBP 2a under conditions in which small fractions of bacterial cells were resistant. In a study with transposon mutants of MRSAs selected for their reduced resistance, the mutants retained an intact $m e c A$, and its product, PBP $2 \mathrm{a}$, also remained unaffected despite the massive reduction in the methicillin MIC of the mutants (13). Biochemical analysis of these mutants indicated that the inserts were in genes involved in staphylococcal cell wall synthesis (13). Ryffel, et al. (19) reported that the high-level resistance expressed by a minority population of methicillin-resistant staphylococci was due to one or more chromosomal mutations $\left(c h r^{\star}\right)$ located outside of $m e c A$, the gene encoding PBP $2 \mathrm{a}$. One of the most probable hypotheses to explain the mutation is that MRSA might acquire the ability to provide PBP 2a with sufficient quantities of the precursors on the nascent cross wall of the staphylococcal cell (15).

Hanaki, et al. (30) reported that Mu3 and Mu50 strains produced three to five times the amount of PBP 2a than VCM-susceptible $S$. aureus strains with or without methicillin resistance. In our study, VISA strain Mu3 exhibited the highest levels of PBP 2a among the 14 strains examined (Fig. 2). VCM exerts its bactericidal effect by binding to Dalanyl-D-alanine (D-Ala-D-Ala) residues of peptidoglycan and its precursor units, inhibiting cell wall peptidoglycan synthesis (31). It is commonly accepted that cell wall thickening is responsible for the VCM resistance of VCM-intermediate $S$. aureus (VISA) strains (24, 32). Cui, et al. (31) reported a strong positive correlation between VCM and reduced susceptibilities of VISA to daptomycin, and that this correlation is related to cell wall thickening and slower growth rates in comparison to VCM-susceptible $S$. aureus.

In MRSA, the incorporation of the peptidoglycan precursor into the growing peptidolgycan chain in the presence of a $\beta$-lactam is carried out by cooperation between the transpeptidase activity of PBP $2 \mathrm{a}(\mathrm{mec} A)$ and the transglycosylase activity of PBP
2 (pbp2) $(7,33)$. The $\beta$-lactam ring mimics the $\mathrm{D}$ Ala-D-Ala moiety of the normal peptidoglycan precursors. PBP $2 \mathrm{a}$ has low affinity for the $\beta$-lactam ring of $\beta$-lactams (34). Thus, PBP $2 \mathrm{a}$ might have low affinity for D-Ala-D-Ala in the stem peptide of the precursor, suggesting that the protein would require substantial amounts of the precursor for proper functioning as a transpeptidase. Therefore, although PBP 2a is a key protein in MRSA, not only PBP $2 \mathrm{a}$ production but also the acquisition of other factors, such as an increased ability to supply the precursor, would be required to mediate $\beta$ lactam resistance in MRSA.

In conclusion, there is no direct relationship between the amounts of PBP 2a expressed in MRSAs obtained clinically and MIC values of $\beta$-lactam. This finding is in good accord with the previously proposed two-step model for the development of high-level resistance to $\beta$-lactams in MRSA (12, 15, 35).

\section{ACKNOWLEDGMENTS}

One of the author (M. A. K. P) was granted for Japanese Government (Monbukagakusho) scholarship from the Ministry of Education, Science, and Culture of Japan.

\section{REFERENCES}

1. Diekema DJ, Pfaller MA, Schmitz FJ, Smayevsky J, Bell J, Jones RN, Beach M, SENTRY Participants Group : Survey of Infections Due to Staphylococcus Species : Frequency of Occurrence and Antimicrobial Susceptibility of Isolates Collected in the United States, Canada, Latin America, Europe, and the Western Pacific Region for the SENTRY Antimicrobial Surveillance Program, 1997-1999. Clin Infect Dis 32 : S114-S132, 2001

2. Akcam FZ, Tinaz GB, Kaya O, Tigli A, Ture E, Hosoglu S : Evaluation of methicillin resistance by cefoxitin disk diffusion and PBP 2a latex agglutination test in $m e c A$-positive Staphylococcus aureus, and comparison of mecA with femA $, \mathrm{femB}, \mathrm{femX}$ positivities. Microbiol Res. doi : 10.1016/j.micres.2007.02.012. (Article in Press, 2007)

3. Song MD, Wachi M, Doi D, Ishino $F$, Matsuhashi $\mathrm{M}$ : Evolution of an inducible 
penicillin-target protein in methicillin-resistant Staphylococcus aureus by gene fusion. FEBS Lett $221: 167-171,1987$

4. Wu SW, de Lencastre H, Tomasz A : Recruitment of the mecA gene homologue of Staphylococcus sciuri into a resistance determinant and expression of the resistant phenotype in Staphylococcus aureus. J Bacteriol 183 : 24172424, 2001

5. Wu SW, de Lencastre H, Tomasz A : Expression of high-level methicillin resistance in Staphylococcus aureus from the Staphylococcus sciuri mec $A$ homologue : role of mutation(s) in the genetic background and in the coding region of mec A. Microb Drug Resist $11: 215$ 224, 2005

6. Fuda C, Suvorov M, Shi Q, Hesek D, Lee M, Mobashery S : Shared functional attributes between the mecA gene product of Staphylococcus sciuri and penicillin-binding protein 2a of methicillin-resistant Staphylococcus aureus. Biochemistry $46: 8050-8057,2007$

7. Goldstein F, Perutka J, Cuirolo A, Plata K, Faccone D, Morris J, Sournia A, Kitzis MD, Ly A, Archer G, Rosato AE : Identification and phenotypic characterization of a beta-lactamdependent, methicillin-resistant Staphylococcus aureus strain. Antimicrob Agents Chemother 51 : 2514-2522, 2007

8. Goffin C, Ghuysen JM : Multimodular penicillinbinding proteins:an enigmatic family of orthologs and paralogs. Microbiol Mol Biol Rev 62 : 1079-1093, 1998

9. Hartman BJ, Tomasz A : Low-affinity penicillinbinding protein associated with beta-lactam resistance in Staphylococcus aureus. J Bacteriol 158: 513-516, 1984

10. Reynolds PE, Brown DF : Penicillin-binding proteins of beta-lactam-resistant strains of Staphylococcus aureus. Effect of growth conditions. FEBS Lett $192: 28-32,1985$

11. Palavecino $\mathrm{E}:$ Clinical, epidemiological, and laboratory aspects of methicillin-resistant Staphylococcus aureus (MRSA) infections. Methods Mol Biol 391 : 1-11, 2007

12. Shibata H, Shirakata C, Kawasaki H, Sato Y, Kuwahara T, Ohnishi Y, Arakaki N, Higuti T: Flavone markedly affects phenotypic expression of $\beta$-lactam resistance in methicillin-resistant Staphylococcus aureus strains isolated clinically. Biol Pharm Bull 26 : 1478-1483, 2003

13. Tomasz A : "The staphylococcal cell wall”. In :
Fischetti VA, Novick RP, Ferretti JJ, Portnoy DA, Rood JI, eds. Gram-positive pathogens. American Society for Microbiology, Washington DC, 2000 , pp. 463-470

14. Hartman BJ, Tomasz A : Expression of methicillin resistance in heterogeneous strains of Staphylococcus aureus. Antimicrob Agents Chemother 29 : 85-92, 1986

15. Sato Y, Shibata H, Arakaki N, Higuti T:6,7Dihydroxyflavone dramatically intensifies the susceptibility of methicillin-resistant or sensitive Staphylococcus aureus to $\beta$-lactams. Antimicrob Agents Chemother 48 : 1357-1360, 2004

16. Sekiguchi K, Saito M, Yajima R : Detection of methicillin-resistant Staphylococcus aureus (MRSA) with antibodies against synthetic peptides derived from penicillin-binding protein 2'. Microbiol Immunol 39 : 545-550, 1995

17. Higuti T, Negama T, Takigawa M, Uchida J, Yamane T, Asai T, Tani I, Oeda K, Shimizu M, Nakamura K, Ohkawa $\mathrm{H}$ : A hydrophobic protein, chargerin II, purified from rat liver mitochondria is encoded in the unidentified reading frame A6L of mitochondrial DNA. J Biol Chem 263 : 6772-6776, 1988

18. Oliver B, Wolfgang B, Gerhard P : Regulation of $\beta$-lactamase synthesis as a novel site of action for suppression of methicillin resistance in Staphylococcus aureus. Zentbl Bakteriol 285 : 413-430, 1997

19. Ryffel C, Strassle A, Kayser FH, Berger-Bächi $\mathrm{B}:$ Mechanisms of heteroresistance in methicillin-resistant Staphylococcus aureus. Antimicrob Agents Chemother 38 : 724-728, 1994

20. Kondo N, Kuwahara-arai K, Kurodamurakami H, Tateda-suzuki E, Hiramatsu K : Eagle-type methicillin resistance : new phenotype of high methicillin resistance under mec regulator gene control. Antimicrob Agents Chemother $45: 815-824,2001$

21. Tomasz A, Nachman S, Leaf $H$ : Stable classes of phenotypic expression in methicillin-resistant clinical isolates of staphylococci. Antimicrob Agents Chemother 35 : 124-129, 1991

22. Araj GF, Talhouk RS, Simaan CJ, Maasad MJ : Discrepancies between mecA PCR and conventional tests used for detection of methicillin resistant Staphylococcus aureus. Int J Antimicrob Agents 11: 47-52, 1999

23. Kuroda M, Ohta T, Uchiyama I, Baba T, Yuzawa H, Kobayashi I, Cui L, Oguchi A, Aoki 
$\mathrm{K}$, Nagai Y: Whole genome sequencing of methicillin-resistant Staphylococcus aureus. Lancet 357 : 1225-1240, 2001

24. Ohta T, Hirakawa H, Morikawa K, Maruyama A, Inose Y, Yamashita A, Oshima K, Kuroda M, Hattori M, Hiramatsu K, Kuhara S, Hayashi $\mathrm{H}:$ Nucleotide substitutions in Staphylococcus aureus strains, Mu50, Mu3, and N315. DNA Res $29: 51-56,2004$

25. Hiramatsu K: Molecular evolution of MRSA. Microbiol Immunol 39 : 531-543, 1995

26. Ryffel C, Kayser FH, Berger-Bächi B : Correlation between regulation of mecA transcription and expression of methicillin resistance in staphylococci. Antimicrob Agents Chemother 36 : 25-31, 1992

27. Petinaki E, Arvaniti A, Bartzavali C, Dimitracopoulos G, Spiliopoulou I : Presence of $m e c A$ genes and overproduction of betalactamase in the expression of low-level methicillin resistance among staphylococci. Chemother 48 : 174-181, 2002

28. McDougal LK, Thornsberry $\mathrm{C}$ : The role of beta-lactamase in staphylococcal resistance to penicillinase-resistant penicillins and cephalosporins. J Clin Microbiol 23 : 832-839, 1986

29. Murakami K, Nomura K, Doi M, Yoshida T : Production of low-affinity penicillin-binding protein by low and high-resistance groups of methicillin-resistant Staphylococcus aureus. Antimicrob Agents Chemother 31 : 1307-1311, 1987

30. Hanaki H, Kuwahara-Arai K, Boyle-Vavra S, Daum RS, Labischinski H, Hiramatsu K : Acti- vated cell-wall synthesis is associated with vancomycin resistance in methicillin-resistant Staphylococcus aureus clinical strains $\mathrm{Mu} 3$ and Mu50. J Antimicrob Chemother 42 : 199-209, 1998

31. Cui L, Tominaga E, Neoh HM, Hiramatsu K : Correlation between reduced daptomycin susceptibility and vancomycin resistance in vancomycin-intermediate Staphylococcus aureus. Antimicrob Agents Chemother $50: 1079-1082$, 2006

32. Cui L, Ma X, Sato K, Okuma K, Tenover FC, Mamizuka EM, Gemmell CG, Kim MN, Ploy M, El-Solh CN, Ferraz V, Hiramatsu K : Cell wall thickening is a common feature of vancomycin resistance in Staphylococcus aureus. J Clin Microbiol 41 : 5-14, 2003

33. Boyle-Vavra S, Yin S, Daum RS : The VraS/ VraR two-component regulatory system required for oxacillin resistance in communityacquired methicillin-resistant Staphylococcus aureus. FEMS Microbiol Lett $262: 163-171$, 2006

34. Berger-Bächi B, Rohrer S : Factors influencing methicillin resistance in staphylococci. Arch Microbiol 178 : 165-171, 2002

35. Sato Y, Shibata H, Arai T, Yamamoto A, Okimura Y, Arakaki N, Higuti T: Variation in synergistic activity by flavone and its related compounds on the increased susceptibility of various strains of methicillin-resistant Staphylococcus aureus to $\beta$-lactam antibiotics. Int $\mathrm{J}$ Antimicrob Agents 24 : 28-35, 2004 